\title{
RNPs and autoimmunity: 20 years later
}

\author{
SANDRA WOLIN \\ Yale University School of Medicine, New Haven, Connecticut 06510, USA
}

In response to Tim's invitation to reflect on a significant advance in the RNA field, I chose a "bedside to bench and back again" story that has now revealed the centrality of autoantibodies and their RNP targets in the development of autoimmune diseases such as systemic lupus erythematosus. Because this story may not be well known to some readers of RNA, I recount it in some detail below.

Back in 1995, the use of antibodies from patients suffering from systemic lupus erythematosus to discover spliceosomal snRNPs and other ribonucleoprotein particles was a classic "bedside to bench" story. Beginning with the 1966 report of the "Sm" autoantigen, several immunologists and rheumatologists, including Henry Kunkel, Eng Tan, and Morris Reichlin, remarkably discovered that patients with systemic lupus erythematosus produced antibodies against their own cellular antigens. The initial characterization revealed that one antigen (called "RNP") was a ribonucleoprotein that was physically associated with a fraction of the Sm antigen. It is well known that Michael Lerner and Joan Steitz used these antibodies to discover that two previously described noncoding RNAs (ncRNAs) of unknown function, the U1 and U2 snRNAs, were complexed with "Sm proteins" and that three novel ncRNAs, which they named U4, U5, and U6, were also present in the immunoprecipitates. Moreover, the relationship between Sm and RNP was explained by the finding that anti-RNP antibodies were directed against the U1 snRNP. Using anti-La and anti-Ro antibodies in similar experiments, the Steitz laboratory soon discovered that the La protein was complexed with pre-tRNAs and pre-5S rRNAs and that the Ro autoantigen bound ncRNAs called Y RNAs. Several laboratories, including those of Jack Keene, Sally Hoch, and Walther van Venrooij, used patient autoantibodies to screen cDNA expression libraries, resulting in the discovery, by the groups of Gideon Dreyfuss and Jack Keene, of the RNA-binding motif known as the RRM or RNP domain.

Although the autoantibodies against RNPs were widely used to diagnose lupus and related autoimmune diseases, by 1995 it was generally believed by physicians and basic scientists alike that they played little role in the etiology of the

Corresponding author: sandra.wolin@yale.edu

Article and publication date are at http://www.rnajournal.org/cgi/doi/ 10.1261/rna.050385.115. Freely available online through the RNA Open Access option. disease. There were a few reports that the antibodies could enter cells, react with RNPs and potentially contribute to autoimmune disease by interfering with the functions of their targets. However, many scientists were skeptical that antibodies could penetrate cells and access nuclei in sufficient quantities to affect function. Additionally, as more and more autoantibodies were uncovered in patients with lupus and related autoimmune diseases, the antibodies were often dismissed as epiphenomena, byproducts of the immune system dysregulation in lupus patients.

Due to a remarkable series of findings, it is now clear that the autoantibodies and their RNP targets are central participants in lupus pathogenesis. A critical insight was the discovery by immunologists, such as Ruslan Medzhitov, Charles Janeway, and Bruce Beutler, that certain cells of the immune system contain transmembrane proteins known as toll-like receptors (TLRs), which recognize repeating patterns on pathogens. Another piece of the puzzle was the discovery that the ligand-binding domains of certain TLRs were located within endosomes, a compartment that is topologically equivalent with the outside of a cell. Activation of these receptors by viral nucleic acids initiates a signaling cascade, resulting in the production of type I interferon and inflammatory cytokines. Although one of these TLRs, TLR9, recognizes DNA containing unmethylated $\mathrm{CpG}$ dinucleotides (motifs that are rare in mammalian DNA), the other TLRs are activated by RNA molecules that are relatively common in cellular RNA, such as single-stranded U-rich RNAs in the case of TLR7. The idea was that since the ligand-binding domains were sequestered within a membrane-bound organelle, cellular "self RNAs" would not be accessible for binding. However, the many RNA viruses that enter cells via endocytosis would activate TLRs.

How does this relate to lupus, autoantibodies, and RNPs? In a convergent discovery, several groups demonstrated that specific white blood cells from patients with lupus contained elevated levels of transcripts from interferon-regulated genes. The idea that excess interferon production could result in autoimmune disease was supported by mouse studies and by reports of patients who developed features of lupus after being treated with interferon for viral infections. The most

(C) 2015 Wolin This article, published in RNA, is available under a Creative Commons License (Attribution-NonCommercial 4.0 International), as described at http://creativecommons.org/licenses/by-nc/4.0/. 
prolific interferon-producing cells in the human body, plasmacytoid dendritic cells, express both TLR7 and TLR9, and also express a receptor on their cell surface that allows them to bind and internalize IgG. Thus, in lupus patients, immune complexes that form between the autoantibodies and nucleic acid-containing autoantigens released by dying cells can be delivered to endosomes, allowing the DNA or RNA moiety to activate the respective TLR, triggering interferon production and an inflammatory cascade.

Remarkably, studies in both mice and patients indicate that autoantibodies against RNPs may be more central to lupus pathogenesis than those against DNA-containing autoantigens such as nucleosomes. For example, studies from Mark Shlomchik's laboratory revealed that autoimmuneprone mice lacking TLR9 failed to make antibodies to DNA-containing autoantigens, yet had more severe renal disease and increased mortality. Conversely, similar mice deleted for TLR7 have greatly reduced titers of antibodies to RNPs and less fulminant disease. Consistent with a central role for autoantibodies against RNPs in the etiology of human lupus, several longitudinal studies have found that, in people who go on to develop clinical lupus, the earliest detected autoantibodies are against Ro RNPs and the U1 snRNP. These antibodies are present years before antibodies to DNA are detected.

Why do antibodies against nucleoproteins develop? While the factors that initiate lupus autoimmunity remain uncertain, pioneering studies from Ann Marshak-Rothstein's laboratory support a model in which nucleoproteins, unlike proteins, are uniquely potent activators of autoreactive B cells because they can both sequentially interact with B cell receptors on the surface of these cells and, upon delivery to endosomes, engage TLRs via their nucleic acid moieties. These findings provide a rationale for why nucleic acid-containing particles are the major autoantigens in lupus and related diseases. Additionally, there is growing evidence that excess cellular RNA and DNA, by stimulating cytosolic nucleic acid sensors, drive an interferon response that, by revving up the immune system, contributes to the initial disease development.

These findings are exciting on many levels. Most importantly, these studies have identified numerous new therapeutic targets for a terrible disease in which current therapies are woefully inadequate. Even given the notoriously long lag time between basic science discoveries and the development and approval of new drugs, I believe that 20 years from now, lupus will be a far more manageable and possibly preventable disease. On a personal note, I was an M.D.-Ph.D. student at Yale in the 1980's. In my medicine rotations, I worked with lupus patients, and saw firsthand both how devastating the disease could be and how little clinical medicine had to offer these patients in the way of treatments. As a graduate student in Joan Steitz's laboratory, I used patient sera to characterize the Ro $60 \mathrm{kDa}$ protein (Ro60) and its associated Y RNAs, starting a project that continues in my laboratory to this day. Although I made the difficult decision to forego a medicine residency and become a pure basic scientist, I remained hopeful that my studies would be of use in ameliorating disease. Gratifyingly, our structure of the Ro60 autoantigen, obtained in collaboration with Karin Reinisch's group, has been useful for mapping epitopes recognized by patient autoantibodies, and our plasmids and cells lines have been used to study how immune complexes formed between patient anti-Ro antibodies and Ro60 RNPs contribute to disease. Moreover, because several studies have revealed that the earliest detected autoantibodies in patients react with Ro60, and some disease manifestations in patients are invariably associated with anti-Ro antibodies, we have begun to collaborate with clinicians to dissect the disease mechanisms.

Finally, I want to give a shout-out to Tim and the RNA journal. I met Tim at the 1983 CSHL RNA Processing meeting, a meeting where I gave my first scientific talk. Upon seeing my name-tag, Tim told me that he had read my recent paper, and that he could tell that "it had to be somebody's thesis." Ever since that initial encounter, he has been a valued colleague and mentor. Among the many things that I admire about Tim are his broad knowledge of RNA biology, his open-mindedness as to what constitutes good science, and his unrelenting support of junior scientists. Moreover, in an era where the term "important paper" has been perverted to mean "published in a CNS journal," or "immediately racked up hundreds of citations," Tim has always understood that some groundbreaking papers can be a difficult "sell," particularly if they focus on an unusual organism, report a negative result, or are simply ahead of their time. From its incarnation, the RNA journal has always been a place where the underlying science is evaluated fairly and on its own merits. Indeed, the many RNA papers that are now recognized as "classics" in their fields are a tribute to both Tim and the journal. 

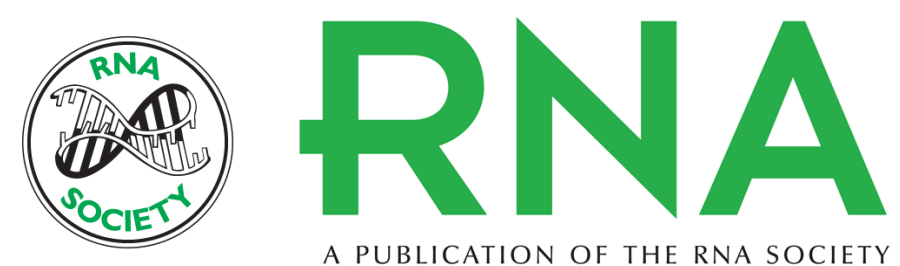

A PUBLICATION OF THE RNA SOCIETY

\section{RNPs and autoimmunity: 20 years later}

Sandra Wolin

RNA 2015 21: 548-549

Open Access Freely available online through the RNA Open Access option.

Creative This article, published in $R N A$, is available under a Creative Commons License Commons (Attribution-NonCommercial 4.0 International), as described at

License http://creativecommons.org/licenses/by-nc/4.0/.

Email Alerting Receive free email alerts when new articles cite this article - sign up in the box at the Service top right corner of the article or click here.

To subscribe to $R N A$ go to:

http://rnajournal.cshlp.org/subscriptions

(C) 2015 Wolin; Published by Cold Spring Harbor Laboratory Press for the RNA Society 